University of Wollongong

Research Online

Australian Institute for Innovative Materials -

Papers

Australian Institute for Innovative Materials

$1-1-2020$

\title{
Light soaking effect driven in porphyrin dye-sensitized solar cells using 1D TiO2 nanotube photoanodes
}

Jung-Ho Yun

jungho.yun@gmail.com

Attila J. Mozer

University of Wollongong, attila@uow.edu.au

Pawel W. Wagner

University of Wollongong, pawel@uow.edu.au

David Offier

University of Wollongong

Rose Amal

r.amal@unsw.edu.au

See next page for additional authors

Follow this and additional works at: https://ro.uow.edu.au/aiimpapers

Part of the Engineering Commons, and the Physical Sciences and Mathematics Commons

Research Online is the open access institutional repository for the University of Wollongong. For further information contact the UOW Library: research-pubs@uow.edu.au 


\title{
Light soaking effect driven in porphyrin dye-sensitized solar cells using 1D TiO2 nanotube photoanodes
}

\begin{abstract}
(C) 2020 Light soaking (LS) effect on porphyrin (GD2) dye-sensitized solar cells (DSSCs) using well-ordered TiO2 nanotube (TNT) photoanodes was studied with different lengths of TNTs and LS treatment time. The TNT array possessing longer length and larger tube diameter had improved photoelectrochemical (PEC) property by generating larger photocurrent, and besides provided a larger surface area to yield more dye loading. The LS effect on GD2-applied DSSCs using TNT photoanodes was triggered off in the first 5 min of the LS treatment, and gradually increased during 60 min LS treatment. The improved PEC property and dye loading by longer TNT array $(22 \mu \mathrm{m})$ led to the noticeable enhancement rate of power conversion efficiency from $0.7 \%$ to $1.88 \%$ ( $168 \%$ increase) after 60 min LS treatment, which was more prominent compared to the enhancement of GD2-applied DSSCs using mesoporous TiO2 films. Especially, morphological property of well-ordered 1D TNT photoanodes offers more spaces to facilitate the cation exchange in electrolyte system, leading to enhancing electron injection and reducing recombination under the LS condition. Electrochemical impedance spectroscopy (EIS) results confirmed the contribution of well-aligned 1D TNT structure to significant LS effect in GD2-applied DSSCs. Bode phase and Nyquist plots in EIS results showed the elongated electron lifetime and diffusion length with an increase in TNT length, followed by improving power conversion efficiency with significantly increased Jsc.

\section{Disciplines}

Engineering | Physical Sciences and Mathematics

\section{Publication Details}

Yun, J., Mozer, A., Wagner, P., Offier, D., Amal, R. \& Ng, Y. (2020). Light soaking effect driven in porphyrin dye-sensitized solar cells using 1D TiO2 nanotube photoanodes. Sustainable Materials and Technologies, 24
\end{abstract}

\section{Authors}

Jung-Ho Yun, Attila J. Mozer, Pawel W. Wagner, David Offier, Rose Amal, and Yun Hau Ng 


\title{
Light soaking effect driven in porphyrin dye-sensitized solar cells using $1 \mathrm{D} \mathrm{TiO}_{2}$ nanotube photoanodes
}

\author{
Jung-Ho Yun a,b,*, Attila J. Mozer ${ }^{\mathrm{c}, *}$, Pawel Wagner ${ }^{\mathrm{c}}$, David L. Offier ${ }^{\mathrm{c}}$, Rose Amal ${ }^{\mathrm{b}}$, Yun Hau $\mathrm{Ng}^{\mathrm{b}, \mathrm{d}, *}$ \\ a Nanomaterials Centre, School of Chemical Engineering and Australian Institute for Bioengineering and Nanotechnology (AIBN), The University of Queensland, Brisbane, QLD 4072, Australia \\ ${ }^{b}$ Particle and Catalysis Research Group, School of Chemical Engineering, The University of New South Wales, Sydney, NSW 2052, Australia \\ c ARC Centre of Excellence for Electromaterials Science, Intelligent Polymer Research Institute, University of Wollongong, Wollongong, NSW 2519, Australia \\ d School of Energy and Environment, City University of Hong Kong, Tat Chee Avenue, Kowloon, Hong Kong SAR, China
}

\section{A R T I C L E I N F O}

\section{Article history:}

Received 27 February 2020

Received in revised form 31 March 2020

Accepted 8 April 2020

\section{Keywords:}

$\mathrm{TiO}_{2}$ nanotube

Light soaking

Porphyrin

Dye-sensitized solar cells

Photoelectrodes

Anodization

\begin{abstract}
A B S T R A C T
Light soaking (LS) effect on porphyrin (GD2) dye-sensitized solar cells (DSSCs) using well-ordered $\mathrm{TiO}_{2}$ nanotube (TNT) photoanodes was studied with different lengths of TNTs and LS treatment time. The TNT array possessing longer length and larger tube diameter had improved photoelectrochemical (PEC) property by generating larger photocurrent, and besides provided a larger surface area to yield more dye loading. The LS effect on GD2-applied DSSCs using TNT photoanodes was triggered off in the first 5 min of the LS treatment, and gradually increased during 60 min LS treatment. The improved PEC property and dye loading by longer TNT array ( $22 \mu \mathrm{m})$ led to the noticeable enhancement rate of power conversion efficiency from $0.7 \%$ to $1.88 \%$ ( $168 \%$ increase) after 60 min LS treatment, which was more prominent compared to the enhancement of GD2-applied DSSCs using mesoporous $\mathrm{TiO}_{2}$ films. Especially, morphological property of well-ordered 1D TNT photoanodes offers more spaces to facilitate the cation exchange in electrolyte system, leading to enhancing electron injection and reducing recombination under the LS condition. Electrochemical impedance spectroscopy (EIS) results confirmed the contribution of well-aligned 1D TNT structure to significant LS effect in GD2-applied DSSCs. Bode phase and Nyquist plots in EIS results showed the elongated electron lifetime and diffusion length with an increase in TNT length, followed by improving power conversion efficiency with significantly increased $\mathrm{J}_{\text {sc. }}$
\end{abstract}

(C) 2020 Published by Elsevier B.V.

\section{Introduction}

In the dye-sensitized solar cell (DSSC) research field, $\mathrm{TiO}_{2}$ is a key material as it is employed as a hole blocking layer and light absorbing dye-sensitized active layer in the DSSCs owing to its chemical durability, non-toxicity, and abundance [1,2]. In order to improve the DSSCs' photovoltaic performance, many studies on the fabrication and modification of $\mathrm{TiO}_{2}$ photoanodes have been reported. A variety of structures and morphologies of $\mathrm{TiO}_{2}$ such as mesoporous, nanorod, nanotube and hollow sphere have been studied for DSSCs [3-6]. In fact, the structure and morphology of $\mathrm{TiO}_{2}$ are the important parameters governing dye loading as well as light harvesting capacity, and thus determining the concentration of photogenerated electrons. Besides, the electron injection, transport and recombination rate can be influenced by the electronic and physical properties such as porosity, morphology, crystallinity, and uniformity of the $\mathrm{TiO}_{2}$ structure [3,7-10]. Compared with the conventional DSSCs consisting in mesoporous $\mathrm{TiO}_{2}$

\footnotetext{
* Corresponding authors.

E-mail addresses: j.yun1@uq.edu.au (J.-H. Yun), attila@uow.edu.au (A.J. Mozer), yunhau.ng@cityu.edu.hk (Y.H. Ng).
}

nanoparticles, vertically well-ordered $\mathrm{TiO}_{2}$ nanotube (TNT)-based DSSCs showed improved charge collection by efficiently suppressing the recombination of photogenerated electron-hole pairs through minimizing the concentration of trapping sites, which are normally located in the grain boundaries of randomly aggregated $\mathrm{TiO}_{2}$ particulate films [11-14]. Thus, a unique structural property of $\mathrm{TiO}_{2}$ leads to the improved charge transport property, resulting in increased the power conversion efficiency [15-19].

To date, various Ru-containing dyes, i.e. N719, N3, Z907, and Black dye, have been applied to DSSCs with TNT photoanodes [20-22]. Dubey et al. compared the photovoltaic performance of DSSCs with TNT photoanodes adsorbed with three different dyes such as N3, Z907 and Black dyes, and reported $\mathrm{Z907}$ to show more enhanced performance because of the presence of a long alkyl group suppressing agglomeration [22]. However, such Ru-based dyes act as an adverse factor limiting the commercialization of DSSCs due to the high cost and low abundance of the noble Ru metal. On the other hand, the employment of inexpensive Zn-based porphyrin dyes in DSSCs has attracted great attention in replacing expensive noble Ru-based dyes with the improved efficiency of 13\% [23]. Porphyrin dyes have also been explored to develop DSSCs using TNT photoanodes by controlling 
functional groups and molecular structures of porphyrin [24,25], where both porphyrin binding geometry and TNT morphology play a critical role in charge-collection efficiency [26]. Mozer et al. has found that light soaking (LS) treatment triggered the significant enhancement of short-circuit current density $\left(\mathrm{J}_{\mathrm{sc}}\right)$, open-circuit voltage $\left(\mathrm{V}_{\mathrm{oc}}\right)$, and fill factor (FF) in the case of GD2 type porphyrin dye-applied DSSCs. This was mainly attributed to the improvement of charge injection and reduced electron recombination, induced by aligning porphyrin dye molecules adsorbed on the surfaces of mesoporous $\mathrm{TiO}_{2}[27,28]$. Considering the alignment of porphyrin dye molecules on $\mathrm{TiO}_{2}$ films plays a critical role in the LS effect, the different sizes distribution in inner tube diameter and alignment of the tube diameter changes the accessibility of electrolyte to the $\mathrm{TiO}_{2}$ /dye surface, which may affect the kinetics of ion exchange at the interface. Therefore, it is expected that the LS effect using well-ordered TNT nanotubes is faster compared to mesoporous films. This motivated us to employ the unique 1D-TNT structure to the porphyrin dye-applied DSSCs and investigate the characteristics of the DSSCs with different pre-illumination duration prior to measurement of the photovoltaic performance.

In this work, we presented a significant LS effect of the porphyrin (GD2) dye-sensitized solar cells using 1D-TNT arrays as a photoanode under the controlled light soaking treatment time. First, photoelectrochemical (PEC) measurement was performed to evaluate capability of TNT arrays with different lengths and diameters as a photoanode, followed by employing TNT arrays as a photoanodes to DSSCs. In addition to the typical photovoltaic performance study, we investigated the LS effect by evaluating dye loading of TNT photoanodes with different lengths and performing electrochemical impedance spectroscopy (EIS) measurement to understand electron transport and recombination in GD2 dye system on TNT photoanodes.

\section{Experimental}

\subsection{Fabrication of TNT-based DSSCS}

The TNT arrays ( $6 \times 6 \mathrm{~mm}$ active device area), obtained from 1,5 , and $15 \mathrm{~h}$ of anodization at $60 \mathrm{~V}$ with ethylene glycol containing $0.5 \mathrm{wt}$
$\% \mathrm{NaF}$ and $5 \mathrm{wt} \% \mathrm{H}_{2} \mathrm{O}$, were integrated into a DSSC device. Prior to dye adsorption, TNT array was treated with $0.04 \mathrm{M}$ of $\mathrm{TiCl}_{4}$ at $70{ }^{\circ} \mathrm{C}$ for $30 \mathrm{~min}$ followed by rinsing with water. $\mathrm{TiCl}_{4}$ treated TNT was calcined at $450{ }^{\circ} \mathrm{C}$ for $3 \mathrm{~h}$ and reheated at $450{ }^{\circ} \mathrm{C}$ for $30 \mathrm{~min}$ if not immediately used. For porphyrin-DSSCs, the TNT array was also soaked in $0.2 \mathrm{mM}$ porphyrin dye GD2 ((E) 3-(5,10,15,20-tetra(3,5-dimethylphenyl) porphyrin-2-yl)propenylidenemalonato zinc (II)) solution in anhydrous tetrahydrofuran for $2 \mathrm{~h}$. The GD2 dye was synthesized according to published procedures $[29,30]$. A sandwich-type DSSC was assembled using the dye-sensitized TNT array as a photoanode and platinumdeposited fluorine-doped tin oxide (FTO) glass (Asahi, $\mathrm{R}_{\mathrm{s}} \leq 8 \Omega \mathrm{sq}^{-1}$ ) as a counter electrode separated by a sealant (Surlyn $60 \mu \mathrm{m}$ thickness, Solaronix). The electrolyte was a mixture of $0.1 \mathrm{M}$ LiI, $0.6 \mathrm{M} \mathrm{1,2-}$ dimethyl-3-propylimidazoliumiodide (DMPImI), $0.03 \quad \mathrm{M} \mathrm{I}_{2}$ and $0.5 \mathrm{M}$ t-butylpyridine (tBP) in acetonitrile [31]. The electrolyte was injected to the cell through a hole drilled through the counter electrode with the aid of a vacuum.

\subsection{Characterization of TNT-based DSSCS}

The current-voltage (I-V) curves of the DSSCs were measured using a Keithlely 2400 source measure unit under a calibrated AM 1.5 solar illumination (Oriel) at $100 \mathrm{~mW} \mathrm{~cm}^{-2}$ light intensity. LS treatment was performed by exposing DSSCs under $100 \mathrm{~mW} \mathrm{~cm}^{-2}$ simulated AM 1.5 light at open-circuit for 5-60 min. During the treatment, the temperature of the solar cell was not controlled. The LS treated DSSCs were contained under the dark until I-V measurements in Fig. 3 and Fig. 5. The adsorbed dye concentration was determined by measuring the absorbance of dye solution desorbed from the surface of the TNT array in basic solution. In order to desorb dyes, GD2 dye-adsorbed TNT arrays were immersed in a $0.1 \mathrm{M} \mathrm{NaOH}$ in water and ethanol with 1 to 1 volume ratio and $0.01 \mathrm{M}$ tetrabutylammonium hydroxide (TBAOH) in tetrahydrofuran (THF) for about $40 \mathrm{~min}$, respectively. The absorbance measurement was performed using UV-Vis spectrophotometer (Cary 300, Varian). Electrochemical impedance spectroscopy (EIS) measurements were performed by illuminating the DSSCs with $100 \mathrm{~mW} \mathrm{~cm}^{-2}$ calibrated AM 1.5 illumination at open-circuit conditions between

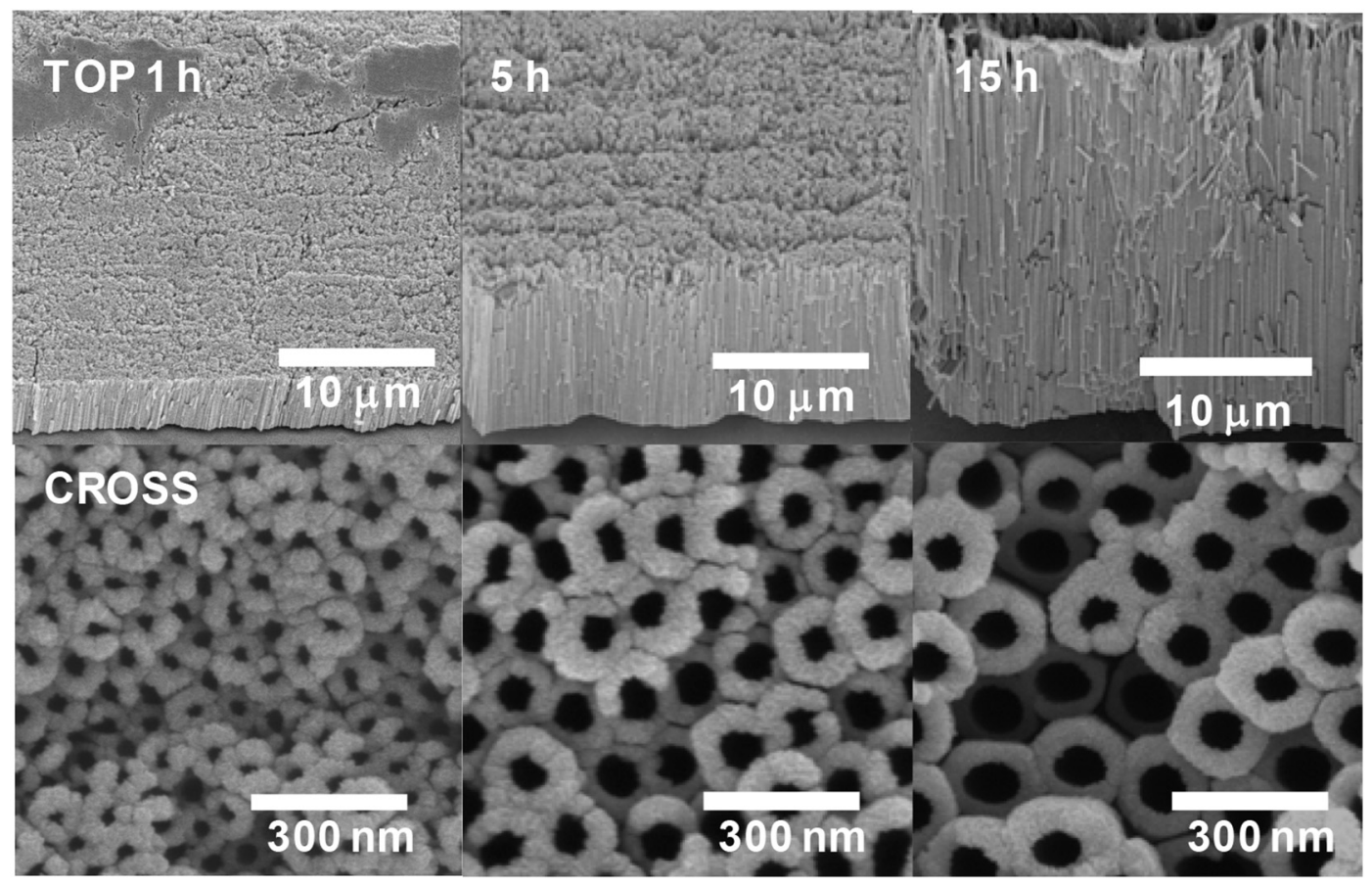

Fig. 1. Top and cross-section SEM images of TNT arrays with different lengths, obtained by different anodization time of 1 h, 5 h, and 15 h. 
$0.1 \mathrm{~Hz}$ and $100 \mathrm{kHz}$ with an AC amplitude of $\pm 10 \mathrm{mV}$ using a Gamry Reference 600 instrument.

\section{Result and discussion}

\subsection{Photoelectrochemical performance of TNT photoanodes}

Fig. 1 shows top view SEM images of well-ordered TNTs prepared by anodization. By varying anodization time of 1,5 , and $15 \mathrm{~h}$, the lengths of TNTs were tuned at ca. 3, 10, and $22 \mu \mathrm{m}$, respectively. The inner tube diameter of TNTs was also changed from $50 \mathrm{~nm}$ to $\sim 100 \mathrm{~nm}$ with an increase in anodization time (see Table 1). The lengths of TNTs presented a significant increase with an increase in anodization time.

Photoelectrochemical measurements were carried out using a threeelectrode system in $0.1 \mathrm{M} \mathrm{Na}_{2} \mathrm{SO}_{4}$ electrolyte under UV illumination. Fig. 2a shows the photocurrent-voltage curves of TNT arrays obtained by different anodization time. TNT arrays were named as TNT1, TNT5, and TNT15 by anodization time of 1,5 , and $15 \mathrm{~h}$, respectively. For all the TNT array samples, the photocurrent density increased with an increase in applied voltages, while the dark current was negligible under the applied voltages ranging from $-1 \mathrm{~V}$ to $1 \mathrm{~V}$ vs $\mathrm{Ag} / \mathrm{AgCl}$. Besides, overall photocurrent density was higher for the TNT arrays obtained by a longer anodization time because of an increase in the length of TNT. The longer TNT array provides the larger $\mathrm{TiO}_{2}$ surface area, which can be photoexcited and interfaced with electrolyte, and thus it contributes to producing more photogenerated electrons and transporting them to the counter electrode during photoexcitation [32-34]. Fig. 2b shows photocurrent response of TNT arrays at $1 \mathrm{~V}$ vs $\mathrm{Ag} / \mathrm{AgCl}$. The photocurrent responses of all the samples are reproducible during the repetitive on-off light irradiation cycles. They present a spike of photocurrent followed by decay until a stationary-state is saturated. The saturated photocurrent response of TNT array exhibits the obvious enhancement for a longer length of TNT array. This result suggests the longer TNT array has enhanced photoelectrochemical property in terms of larger photo-electron generation rate [33]. In Table 1, the amount of GD2 porphyrin dye adsorbed on TNT array is closely related with the length and inner tube diameter of TNT array. The longer TNT array with larger inner tube diameter provides the larger surface area to afford more anchoring sites for dye-uptake, and thus the increased dye adsorption by the longer TNT array contributes to the improvement of light harvesting efficiency of DSSCs.

\subsection{Light soaking effect of GD2 porphyrin-applied DSSCs using TNT photoanodes}

The light soaking (LS) treatment was performed by exposing DSSCs under the simulated AM 1.5 light source of $100 \mathrm{~mW} \mathrm{~cm}^{-2}$. In fact, a LS treatment accelerates the degradation of the DSSC performance. For example, the typical N719-DSSCs showed the dramatic decrease in $\mathrm{J}_{\mathrm{sc}}$ and $\mathrm{V}_{\mathrm{oc}}$ during LS treatment [35-37]. Wang et al. reported overall efficiency of N719-DSSCs decreased nearly 35\% after LS treatment where main reasons are due to the desorption of dye molecules and the contamination of interfaces between electrolyte and $\mathrm{TiO}_{2}$ surfaces by a LS treatment condition [38,39]. Fig. S1 and Table S1 present that photovoltaic

Table 1

Geometry and amount of GD2 dye loading of TNT arrays obtained by different anodizing time.

\begin{tabular}{lllll}
\hline Sample & $\begin{array}{l}\text { Anodization time } \\
(\mathrm{h})\end{array}$ & $\begin{array}{l}\text { TNT length } \\
(\mu \mathrm{m})\end{array}$ & $\begin{array}{l}\text { Pore diameter } \\
(\mathrm{nm})\end{array}$ & $\begin{array}{l}\text { Dye loading } \\
\left(\times 10^{-7} \mathrm{~mol} \mathrm{~cm}^{-2}\right)\end{array}$ \\
\hline TNT1 & 1 & $3.32 \pm 0.06$ & $50.01 \pm 2.35$ & 0.08 \\
TNT5 & 5 & $10.45 \pm 0.53$ & $78.61 \pm 5.55$ & 0.57 \\
TNT15 & 15 & $22.32 \pm 0.85$ & $98.67 \pm 4.87$ & 0.74 \\
\hline
\end{tabular}

performances of typical N719-applied DSSCs using TNT15 photoanodes have decreased after the LS treatment. Indeed, this LS treatment result on N719-applied DSSCs shows good agreement with the previous reports [37-39].

In contrast to the N719-applied DSSCs, GD2-applied DSSCs show the different tendency in photovoltaic performance with the LS treatment where the LS effect led to the increase in photocurrent by increasing electron injection rate from the excited dye molecules to the $\mathrm{TiO}_{2}[40]$. The photovoltaic performances of the GD2-applied DSSCs with three different TNT lengths $(3,10$, and $22 \mu \mathrm{m}$ in length) were measured before and after $60 \mathrm{~min}$ LS treatment by AM 1.5 solar simulator $\left(100 \mathrm{~mW} \mathrm{~cm}^{-2}\right)$ as seen in Fig. 3. Before LS treatment, the DSSCs using 3, 10, and $22 \mu \mathrm{m}$ long TNT arrays presented the short-circuit current densities $\left(\mathrm{J}_{\mathrm{sc}}\right)$ of $1.36,2.33$, and $2.69 \mathrm{~mA} \mathrm{~cm}^{-2}$, respectively, while the $V_{\text {oc }}$ values were comparable at $0.48-0.49 \mathrm{~V}$ regardless of the lengths of TNT arrays. After 60 min of LS treatment, all DSSCs presented significantly enhanced photovoltaic performances. Therein, the DSSCs using 3, 10 , and $22 \mu \mathrm{m}$ long TNT arrays showed the $\mathrm{J}_{\mathrm{sc}}$ of $1.6,4.58$, and $5.6 \mathrm{~mA} \mathrm{~cm}^{-2}$, the $\mathrm{V}_{\mathrm{oc}}$ of $0.56,0.55$, and $0.53 \mathrm{~V}$, and the power conversion efficiency of $0.55,1.45$, and $1.88 \%$, respectively. From these results in Fig. 3 and Table 2, the increase in $\mathrm{J}_{\mathrm{sc}}$ with the increase in the lengths of TNT arrays can be attributed to a relatively larger surface area to absorb a larger amount of dyes (see Table 1) and an efficient cation exchange between dye molecule and electrolyte. It will be further discussed in the following section. In the meantime, the dye loading amount of mesoporous $\mathrm{TiO}_{2}$ films (in 3-4 $\mu \mathrm{m}$ thick) was approximately 10 times higher $\left(0.9 \times 10^{-7} \mathrm{~mol} \mathrm{~cm}^{-2}\right)$ than that of TNT1 arrays, and thus the initial device performance of TNT-based GD2-DSSCs was much lower compared to the mesoporous $\mathrm{TiO}_{2}$ film-based devices [41]. Instead, LS effect of TNT-based GD2-DSSCs showed a relatively large magnitude in device performance, particularly, $\mathrm{J}_{\mathrm{sc}}$, compared to mesoporous $\mathrm{TiO}_{2}$-based GD2-DSSCs, indicating the migration of the chemical species to $\mathrm{TiO}_{2}$ surfaces is facilitated by more sparsely packed surfaces in the reduced dye loaded TNT-based devices [31]. Meanwhile, the big increase in TNT length from $3 \mu \mathrm{m}$ thick to $22 \mu \mathrm{m}$ thick resulted in the slight decrease in $\mathrm{V}_{\mathrm{oc}}$. Although it was not a significant change, it can be due to the electron back reaction from conduction band (CB) of TNT to ${ }_{3}^{-}$by the increase in the surface area of the $\mathrm{TiO}_{2}$ and the longer travel distance of the photo-injected electrons [42,43]. In our work, however, the slight decrease in $V_{\text {oc }}$ was not a limiting factor of the overall device performance, while it is important to note that the $V_{\text {oc }}$ increase was observed from all TNT lengths after LS treatment. It indicates LS treatment facilitates photo-injection from dye to $\mathrm{TiO}_{2}$ and retards recombination between $\mathrm{Li}^{+}$ions and electrons by more efficient cation exchange (see Fig. 6).

Mozer et al. demonstrated the origin of the lower $V_{\text {oc }}$ of the GD2applied DSSCs compared to the $\mathrm{V}_{\text {oc }}$ of the N719-applied DSSCs by investigating electron transport properties of the N719- and the GD2applied DSSCs. It was found that a significantly reduced electron lifetime of the GD2-applied DSSCs was the main reason for the lower $\mathrm{V}_{\mathrm{oc}}$. Herein, the reduced electron lifetime originates from different intermolecular interaction between GD2 porphyrin dye / $\mathrm{I}_{3}^{-}$and N719 dye $/ \mathrm{I}_{3}^{-}$[44]. In order to investigate the main parameter affecting the efficiency before and after LS treatment, the enhancement degree of photovoltaic performances was considered. In Fig. 4, after 60 min LS treatment, the enhancement of $V_{\text {oc }}$ increased to $\sim 15 \%$, which was comparable among different lengths of TNT arrays, while $\mathrm{J}_{\mathrm{sc}}$ increased significantly with an increase in the lengths of TNT arrays. The enhancement of the $\mathrm{J}_{\mathrm{sc}}$ was from 1.36 to $1.60 \mathrm{~mA} \mathrm{~cm}{ }^{-2}$ (18\% increase) for $3 \mu \mathrm{m}$, from 2.33 to $4.58 \mathrm{~mA} \mathrm{~cm}^{-2}$ (96\% increase) for $10 \mu \mathrm{m}$, and from 2.69 to $5.60 \mathrm{~mA} \mathrm{~cm}{ }^{-2}$ (108\% increase) for $22 \mu \mathrm{m}$, accompanying drastically enhanced efficiencies: from 0.37 to $0.55 \%$ ( $49 \%$ increase) for $3 \mu \mathrm{m}$, from 0.59 to $1.45 \%$ ( $146 \%$ increase) for $10 \mu \mathrm{m}$, and from 0.70 to $1.88 \%$ ( $168 \%$ increase) for $22 \mu \mathrm{m}$. Therefore, the major reason of the improved efficiency after LS treatment can be ascribed to the significant increase in $\mathrm{J}_{\mathrm{sc}}$. 
(a)

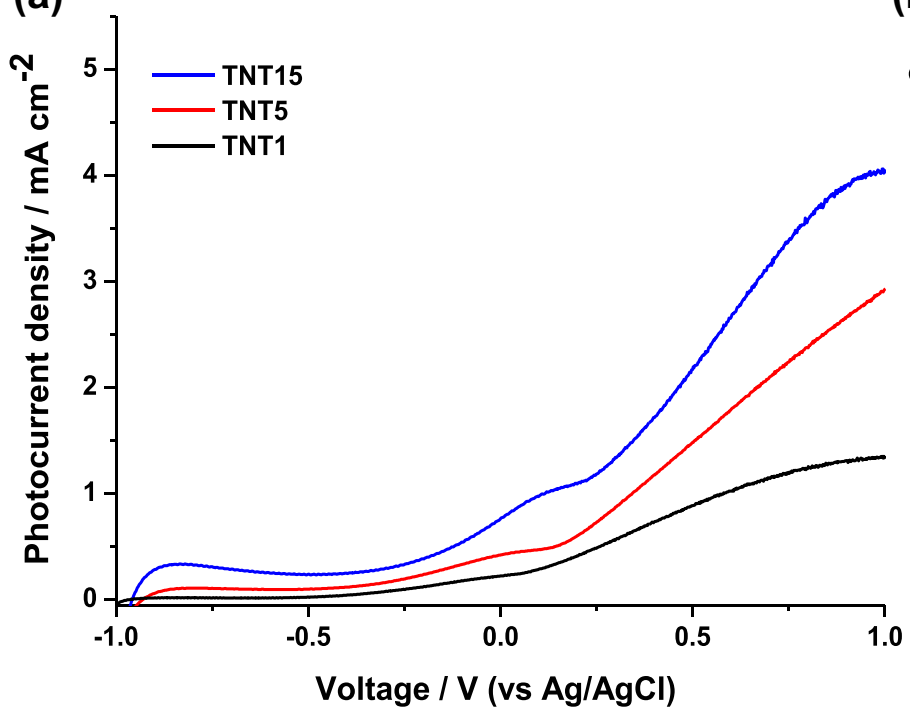

(b)

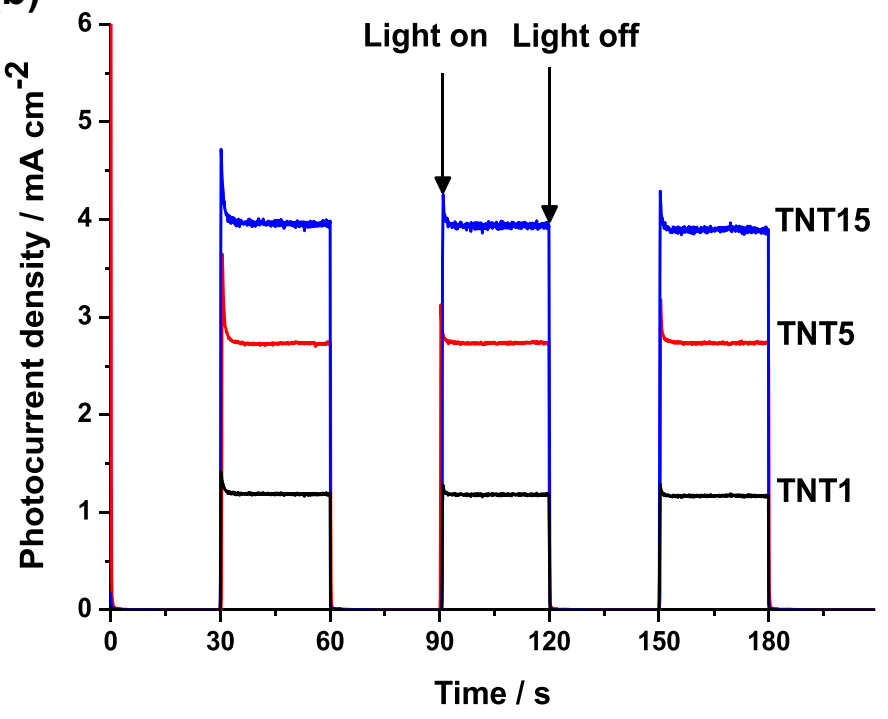

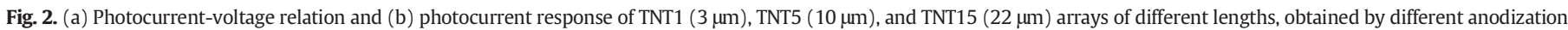

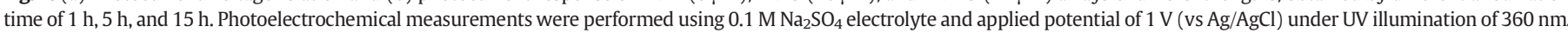

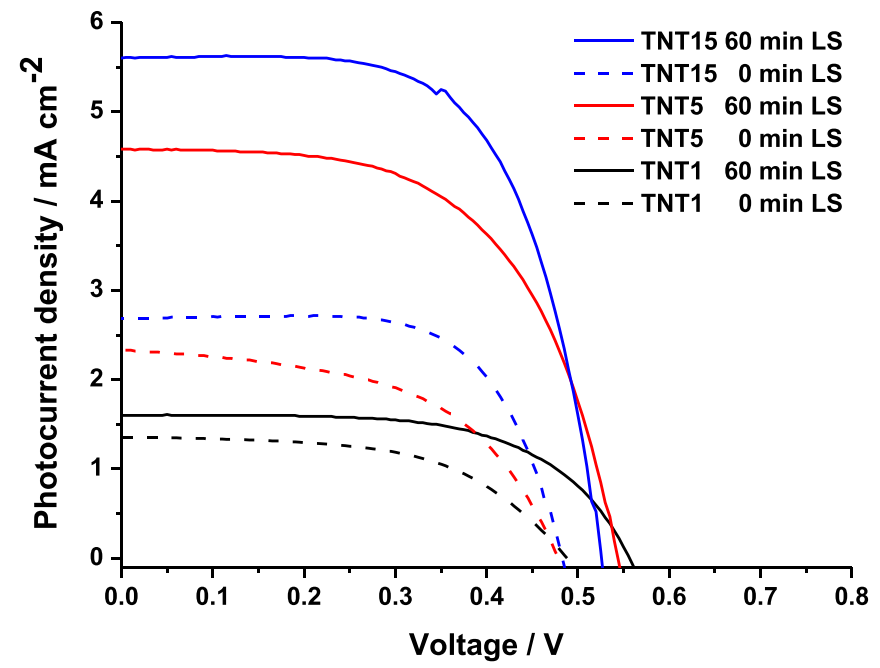

Fig. 3. Photocurrent-voltage characteristics of GD2-applied DSSCs fabricated using TNT1 $(3 \mu \mathrm{m})$, TNT5 $(10 \mu \mathrm{m})$, and TNT15 $(22 \mu \mathrm{m})$ photoanodes of different lengths with light soaking treatment ( 0 min and 60 min light soaking) under AM 1.5 solar simulator $\left(100 \mathrm{~mW} \mathrm{~cm}^{-2}\right)$.

Table 2

Photovoltaic performance of GD2-applied DSSCs using different TNT arrays under $60 \mathrm{~min}$ light soaking (LS) treatment by AM 1.5 solar simulator $\left(100 \mathrm{~mW} \mathrm{~cm}^{-2}\right)$.

\begin{tabular}{llllll}
\hline Sample & LS time & $\mathrm{V}_{\mathrm{oc}}(\mathrm{V})$ & $\mathrm{J}_{\mathrm{sc}}\left(\mathrm{mA} \mathrm{cm}^{-2}\right)$ & $\mathrm{FF}$ & Efficiency (\%) \\
\hline TNT1 & Initial & 0.49 & 1.36 & 0.56 & 0.37 \\
& $60 \mathrm{~min}$ & 0.56 & 1.60 & 0.61 & 0.55 \\
TNT5 & Initial & 0.48 & 2.33 & 0.53 & 0.59 \\
& 60 min & 0.55 & 4.58 & 0.58 & 1.45 \\
TNT15 & Initial & 0.48 & 2.69 & 0.66 & 0.70 \\
& 60 min & 0.53 & 5.60 & 0.63 & 1.88 \\
\hline
\end{tabular}

Fig. 5 exhibits the photovoltaic performances of the GD2-applied DSSCs using TNT1, TNT5, and TNT15 arrays with different lengths under LS treatment duration. The DSSCs were initially measured under AM 1.5 solar simulator $\left(100 \mathrm{~mW} \mathrm{~cm}^{-2}\right)$, treatment was

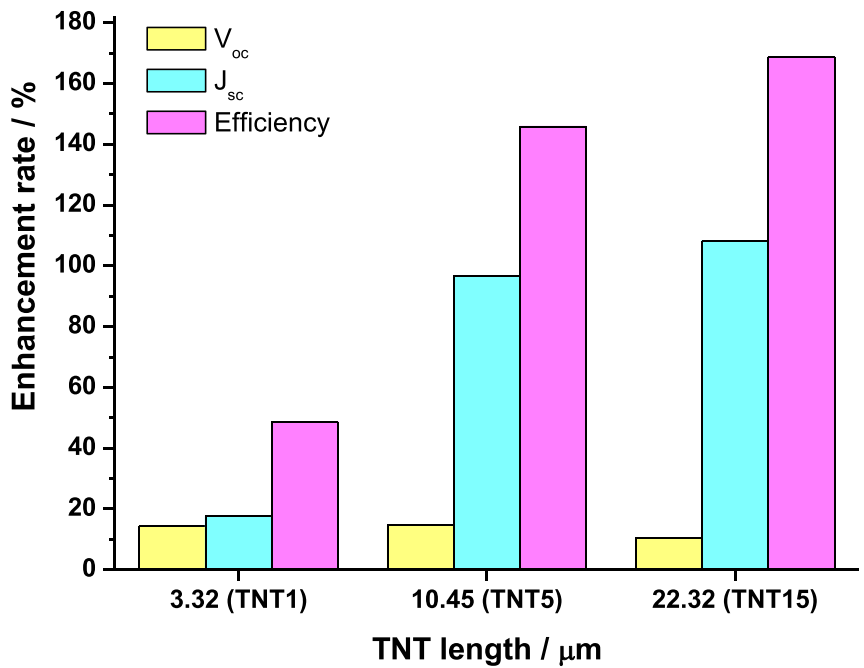

Fig. 4. Enhancement rate of photovoltaic performances ( $V_{o c}, J_{s c}$, and efficiency) in GD2 applied DSSCs fabricated using TNT1 $(3 \mu \mathrm{m})$, TNT5 $(10 \mu \mathrm{m})$, and TNT15 (22 $\mu \mathrm{m})$ photoanodes of different lengths after 60 min LS treatment under AM 1.5 solar simulator $\left(100 \mathrm{~mW} \mathrm{~cm}^{-2}\right)$.

performed by changing the illumination time on the same sample under AM 1.5 solar simulator $\left(100 \mathrm{~mW} \mathrm{~cm}^{-2}\right)$, and re-measured at identified LS treatment time. Wagner et al. found that the improvement in the photovoltaic performances of the GD2-applied DSSCs occurred within the first 60 min LS treatment and the improved photovoltaic performances lasted for 3 months [27]. In this work, it was found that $\mathrm{V}_{\mathrm{oc}}$, $\mathrm{J}_{\mathrm{sc}}$, and power conversion efficiency of DSSCs using TNT5 and TNT15 increased drastically within $5 \mathrm{~min}$, and subsequently the values became gradually saturating, indicating the LS effect was triggered off at the very beginning of the LS treatment. For DSSCs with TNT1, however, it showed a less profound enhancement in $\mathrm{J}_{\mathrm{sc}}$ and power conversion efficiency compared to other two samples. It is possible that the short TNT is already light soaked during the first JV measurement, and therefore the change by subsequent light soaking is less. In addition to the adsorbed dye amount effect, there may be another possible factor affecting the significant LS effect on 1D TNT photoanodes. Wagner et al. 


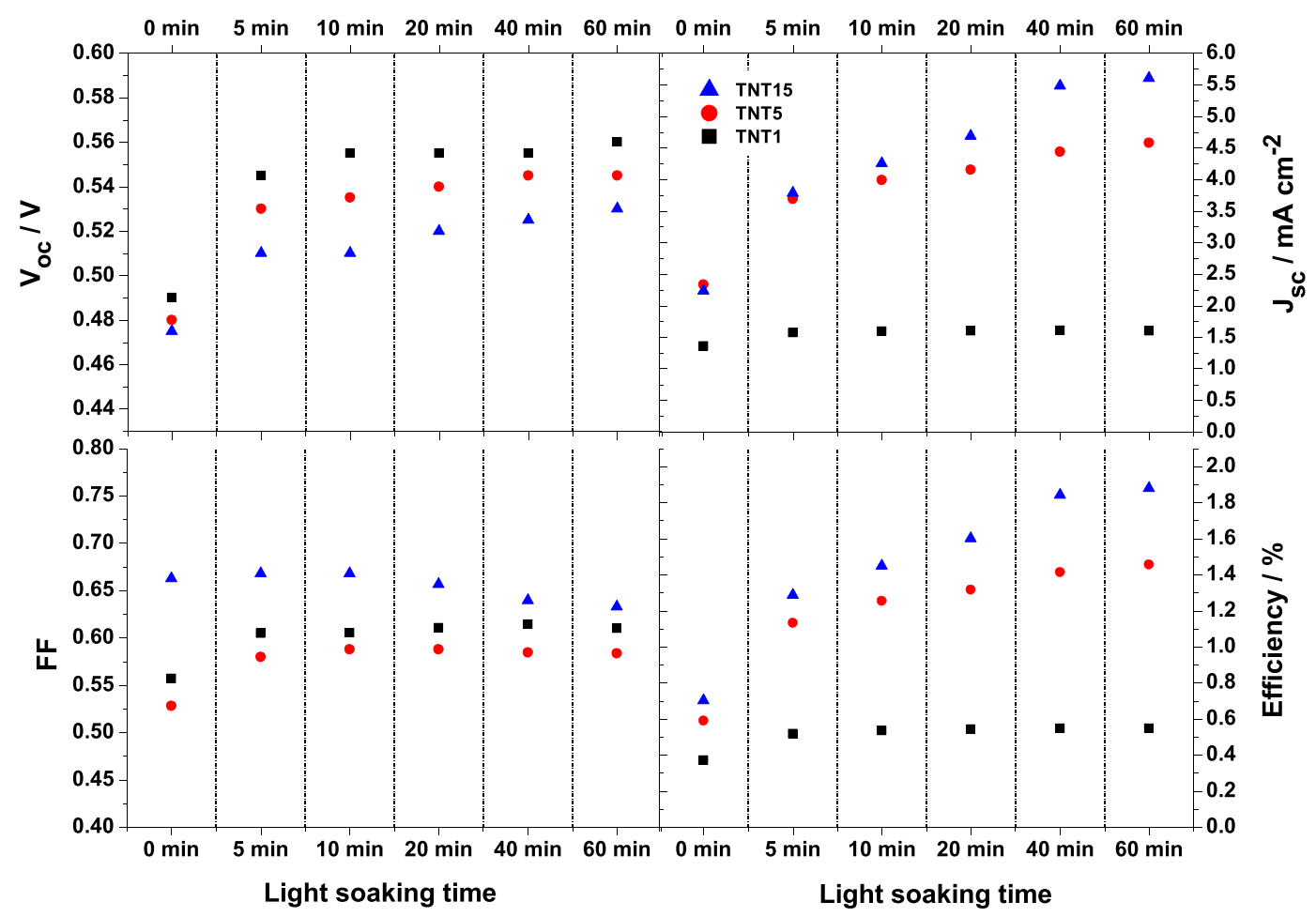

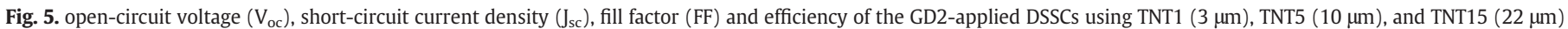
photoanodes of different TNT lengths with an increase in LS time.

reported 26\% improved efficiency in average with GD2-applied mesoporous $\mathrm{TiO}_{2}$ photoanode system after $1 \mathrm{~h}$ LS treatment, while this work with GD2-applied 1D TNT photoanode system shows 168\% efficiency enhancement from 0.70 to $1.88 \%$ on TNT15 sample. It indicates that such significant LS effect in this work may be due to facilitation of dye molecule rearrangement on unique 1D TNT structure rather than on mesoporous $\mathrm{TiO}_{2}$ films.

Herein, efficient ion migration between the rearranged dye molecules and electrolytes on 1D TNT photoanodes can lead to the decrease in recombination with redox couples and the improved electron injection, followed by enhancing efficiency with an increase in $\mathrm{J}_{\mathrm{sc}}$ and $\mathrm{V}_{\mathrm{oc}}$. Specifically, the correlation between charge transport at the interface of $\mathrm{TiO}_{2} /$ dye/electrolyte and TNT morphology (inner tube diameter \& length) will be further discussed in interpreting EIS result below. $[27,45,46]$

As seen in Fig. 6, Griffith et al. proposed surface $\mathrm{Li}^{+}$species, initially associated with a carboxyl group of two carboxyl groups in GD2 dye, prevent electron injection from $\mathrm{Zn}$, and besides lead to rapid recombination. However, under the illumination, the created dye cations induce the exchange of $\mathrm{Li}^{+}$with DMPIm${ }^{+}$by removing $\mathrm{Li}^{+}$ions located onto the $\mathrm{TiO}_{2}$ surfaces through Columbic repulsion. Then, the empty spaces by the removal of $\mathrm{Li}^{+}$enhance electron injection and limit recombination process. Herein, widening interparticle channels inside $\mathrm{TiO}_{2}$ electrode materials can contribute to enhancing mass transport of chemical species in electrolytes [47]. For instance, compared to the conventional mesoporous $\mathrm{TiO}_{2}$ films, well-aligned tubular channels of 1DTNT arrays offer longer mean free paths, leading to efficiently penetrating dye molecules and electrolytes inside TNT arrays [48]. As the mean free path can be explained by electron transfer resistance $\left(R_{t r}\right)$ along with $\mathrm{TiO}_{2}$ network and electron diffusion length $(L)$, the electron diffusion length $(L)$ is proportional to the mean free path [49]. Schmuki et al. reported around 20 times longer diffusion lengths of TNT arrays than that of $\mathrm{TiO}_{2}$ nanoparticle films, indicating 1D TNT arrays possess longer mean free path [50]. In the meantime, the mesoporous $\mathrm{TiO}_{2}$ film system with shorter mean free path would result in slower cation exchange by (a)
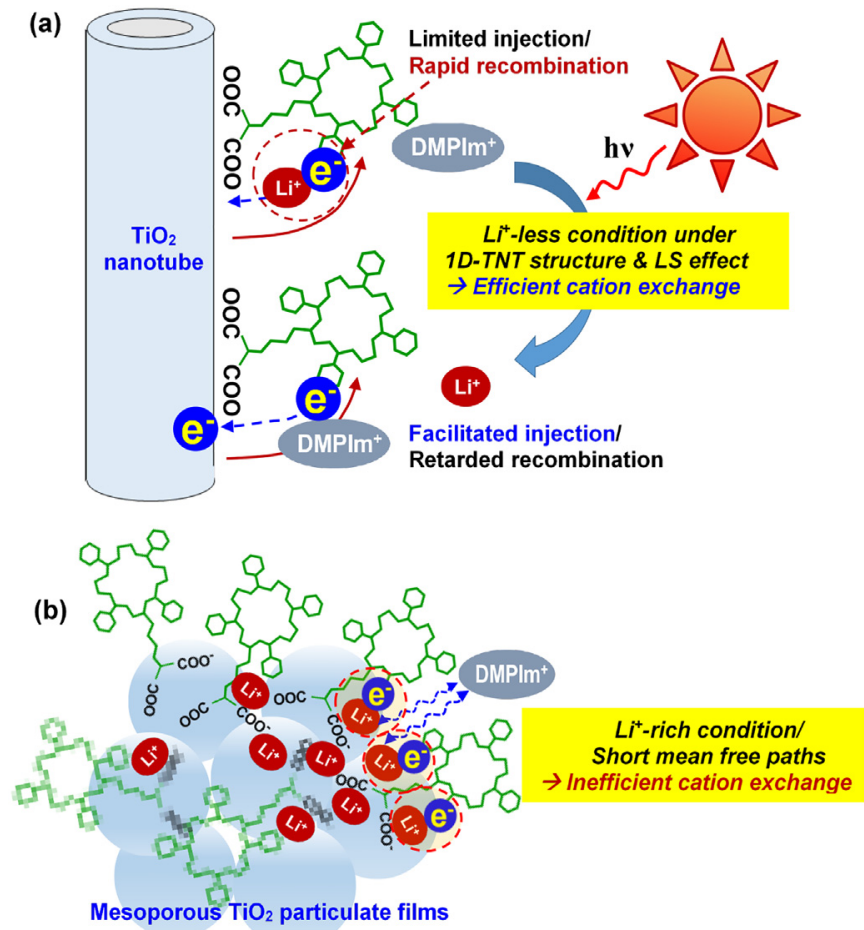

Fig. 6. Schematic diagrams on charge injection and recombination mechanism through cation exchange in (a) $\mathrm{Li}^{+}$-less condition of $1 \mathrm{D} \mathrm{TiO}_{2}$ nanotube and (b) $\mathrm{Li}^{+}$-rich condition of randomly oriented mesoporous $\mathrm{TiO}_{2}$ particulate films, driven by light soaking treatment. 
retarding ion migration owing to the presence of aggregated dye molecules and complicated pores in randomly oriented mesoporous $\mathrm{TiO}_{2}$ structure. In this regard, the amount of $\mathrm{Li}^{+}$ions occupied onto the more sparsely packed GD2-sensitized TNT arrays would be relatively lower, indicating such $\mathrm{Li}^{+}$-less condition of the GD2-sensitized TNT array leads to more efficient cation exchange between $\mathrm{Li}^{+}$ions and DMPIm $^{+}$ions under LS treatment, compared to the relative $\mathrm{L}^{+}$-rich condition of the GD2-sensitized mesoporous $\mathrm{TiO}_{2}$ films. Thus, employing 1D-TNT photoelectrodes can be a possible strategy to improve the cation exchange rate during LS treatment in GD2-DSSC system, leading to the obvious LS effect to enhance overall photovoltaic performances through efficient electron injection and less recombination [31]. For further investigation of LS effect using the electrochemical impedance spectroscopy (EIS) technique, 60 min LS treated samples with different TNT lengths were employed.

Electrochemical impedance spectroscopy (EIS) measurement provides valuable information for the understanding and characterization of the photovoltaic parameters of the DSSCs. Fig. 7 presents the impedance-frequency plots and the Nyquist plots obtained from electron transfer at the $\mathrm{TiO}_{2}$ and electrolyte interface under AM 1.5 solar simulator. In Fig. 7a, after $1 \mathrm{~h}$ LS treatment, the peak frequencies measured from GD2-applied DSSCs with 3, 10, and $22 \mu \mathrm{m}$ long TNT arrays were $39.72,15.84$, and $7.94 \mathrm{~Hz}$, respectively. The frequencies at main peaks exhibit a shift to lower values with an increase in the lengths of TNT arrays, which indicates longer electron lifetime according to eq. (3). The electron density varies with changing the $\mathrm{TiO}_{2}$ anode thickness. On one hand, the charge generation rate increases due to increased light absorption/injection rate. On the other hand, the $\mathrm{TiO}_{2}$ volume increases
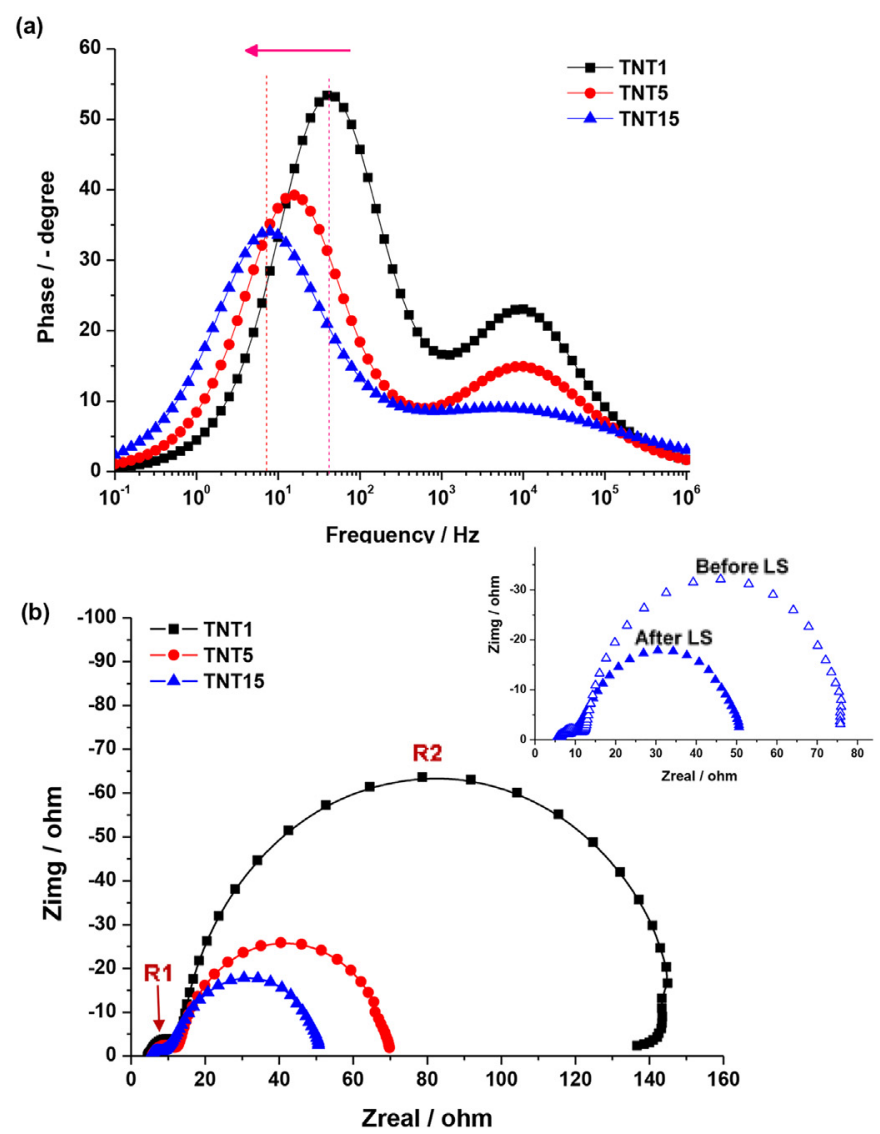

Fig. 7. (a) Bode phase plots and (b) Nyquist plots of GD2-applied DSSCs fabricated using TNT1 $(3 \mu \mathrm{m})$, TNT5 $(10 \mu \mathrm{m})$, and TNT15 $(22 \mu \mathrm{m})$ photoanodes of different TNT lengths after 60 min LS treatment under AM 1.5 solar simulator of $100 \mathrm{~mW} \mathrm{~cm}^{-2}$ (inset: comparison of Nyquist plots of GD2-applied DSSCs using TNT15 before and after $60 \mathrm{~min}$ LS treatment). at increased thickness influenced by the porosity of the films (see Fig. 1). Lower charge density with increased TNT length could contribute to longer lifetime. Another possibility is reduction in interfacial recombination between the Ti foil substrate and the electrolyte in using longer TNTs due to better passivation of this interface at longer anodising condition [5,51]. Jennings et al. reported that the electron diffusion length ( $L$ in eq. (4)) in $\mathrm{TiO}_{2}$ nanotube-applied N719-DSSCs was much longer than that of the tube lengths [52]. The longer electron lifetime in the longer TNT array can lead to increasing electron diffusion length from eq. (4), followed by higher $\mathrm{J}_{\mathrm{sc}}$ and $\mathrm{FF}$.

$\tau=1 /\left(2 \pi f_{\text {peak }}\right)$

$L=(\mathrm{D} \tau)^{1 / 2}=\mathrm{d}\left(\mathrm{R}_{\mathrm{rec}} / \mathrm{R}_{\mathrm{tr}}\right)^{1 / 2}$

where $\tau$, $f_{\text {peak }}, \mathrm{R}_{\mathrm{rec}}, \mathrm{R}_{\mathrm{tr}}$, and d represent the electron lifetime in $\mathrm{TiO}_{2}$, the peak frequency at the second semicircle in Fig. $7 \mathrm{~b}$, recombination resistance, electron transfer resistance and $\mathrm{TiO}_{2}$ tube thickness, respectively. $L$ and D represent electron diffusion length and diffusion coefficient, respectively [53]. In Fig. 7b, the internal resistance of the first semicircle (R1) at high frequency range on the Nyquist plots is attributed to the redox reaction at the electrolyte and counter electrode interface, while semicircle (R2) at low frequency range is attributed to charge recombination between $\mathrm{TiO}_{2}$ electrons and acceptor species in the electrolyte. Herein, the second larger semicircles decreased significantly with the increase in TNT lengths and inner tube diameters, with the R2 values of the TNT1, TNT5, and TNT15 were 129.6, 54.48, and $37.10 \Omega$, respectively, which were correspondent to $\mathrm{R}_{\mathrm{rec}}$. In the meantime, $\mathrm{R}_{\mathrm{tr}}$ was calculated from the 45 degree slope at the transition region between the first and the second semicircles where the $\mathrm{R}_{\mathrm{tr}}$ values of TNT1, TNT5, and TNT15 were 39.72, 37.08, and 27.99 $\Omega$, respectively. According to eq. (4), the electron diffusion lengths for TNT1, TNT5, and TNT15 were calculated to $6.97,11.87$, and $24.00 \mu \mathrm{m}$, respectively, and then the calculated electron diffusion lengths were approximately $20-110 \%$ longer than the $\mathrm{TiO}_{2}$ nanotube thicknesses, indicating that the applied $\mathrm{TiO}_{2}$ nanotube thicknesses were long enough to transfer electrons in the system, and also recombination process was much slower than diffusion through the TNT array [54]. In the meantime, inner tube diameter difference might also be correlated with the charge recombination resistance at the interface of $\mathrm{TiO}_{2} /$ dye/electrolyte. With the length differences, the inner tube diameters of TNT1, TNT3, and TNT15 arrays are $50 \mathrm{~nm}$, $78 \mathrm{~nm}$, and $98 \mathrm{~nm}$, respectively. With the larger tube diameter, a semicircle (R2) of TNT15 is smaller than those of TNT1 and TNT3, indicating that the charge recombination resistance at the interface of $\mathrm{TiO}_{2} /$ dye/ electrolyte is lower, and therefore photoelectrons can be efficiently transferred through efficient cation exchange between $\mathrm{Li}^{+}$and DMPIm $^{+}$. Thus, together with the increase lengths of TNT arrays, it would be explained that the enlarged inner tube diameters of TNT arrays can contribute to enhancing charge transport by improving cation exchange as well.

In addition, Fig. 7b inset result shows the difference of Nyquist plots before and after LS treatment where the smaller second semicircle of the LS treated device indicates more enhanced electron injection and slower recombination in comparison with non-LS treated device. Then, the electron diffusion length of the initial TNT15-employed device (non-LS treated device) was $20.81 \mu \mathrm{m}$, which was shorter than that of the LS treated device. It is evident that LS treatment contributes to enhancing electron transport by facilitating the cation exchange between dye molecule and electrolyte.

\section{Conclusions}

Porphyrin (GD2) dye-sensitized DSSCs using TNT array as a photoanode showed considerably enhanced photovoltaic performances under light soaking (LS) treatment. After LS treatment, the enhancement of short-circuit current density $\left(\mathrm{J}_{\mathrm{sc}}\right)$ showed the greatest increase 
from $2.69 \mathrm{~mA} \mathrm{~cm}^{-2}$ to $5.60 \mathrm{~mA} \mathrm{~cm}^{-2}$ (108\% increase) with an increase in TNT length, attracting the significant increase of energy conversion efficiency from $0.70 \%$ to $1.88 \%$ (168\% increase) for the GD2-applied DSSCs using $22 \mu \mathrm{m}$ long TNT photoanode, which was more improved than that of $\mathrm{TiO}_{2}$ nanoparticle-based DSSCs [27]. It was because of faster cation exchange by well-aligned 1D TNT structured photoanode system under LS treatment condition, leading to excellent electron injection, less recombination, and longer electron diffusion length, followed by significantly improving photovoltaic performance. Meanwhile, the photovoltaic performance of GD2-applied DSSCs using TNT photoanodes showed time-dependent tendency with different LS treatment periods. The enhancement degree of photovoltaic performance with LS treatment time was dramatically prompted within the beginning stage of 5 min LS treatment, followed by gradually saturated photovoltaic performance with an increase in LS treatment time. The EIS results indicated that the enhanced photovoltaic performance after LS treatment was due to the elongated electron lifetime and diffusion length and the reduced internal resistance with an increase in the length of TNT photoanodes.

\section{Declaration of Competing Interest}

The authors declare that they have no known competing financial interests or personal relationships that could have appeared to influence the work reported in this paper.

\section{Acknowledgements}

This research has been partially financially supported by the Australian Research Council (ARC) through Discovery (Project No. DP170104379), DECRA (Project No. DE180101253), and the ARC Centre of Excellence Scheme (Project No. 140100012 CE). We acknowledge scientific and technical assistance of the Queensland node of the Australian National Fabrication Facility (ANFF) at the University of Queensland (UQ) and the Materials Node of ANFF at the University of Wollongong.

\section{Appendix A. Supplementary data}

Supplementary data to this article can be found online at https://doi. org/10.1016/j.susmat.2020.e00165.

\section{References}

[1] H. Spanggaard, F.C. Krebs, A brief history of the development of organic and polymeric photovoltaics, Sol. Energy Mater. Sol. Cells 83 (2-3) (2004) 125-146.

[2] Krebs, F.C., et al., Production of large-area polymer solar cells by industrial silk screen printing lifetime considerations and lamination with polyethyleneterephthalate. Sol. Energy Mater. Sol. Cells, 2004. 83(2-3): p. 293-300.

[3] C.J. Barbé, et al., Nanocrystalline titanium oxide electrodes for photovoltaic applications, J. Am. Ceram. Soc. 80 (12) (1997) 3157-3171.

[4] S.H. Kang, et al., Nanorod-based dye-sensitized solar cells with improved charge collection efficiency, Adv. Mater. 20 (1) (2008) 54-58.

[5] K. Zhu, et al., Enhanced charge-collection efficiencies and light scattering in dyesensitized solar cells using oriented $\mathrm{TiO}_{2}$ nanotubes arrays, Nano Lett. 7 (1) (2006) 69-74

[6] J.H. Park, et al., Nanostructured photoelectrode consisting of $\mathrm{TiO}_{2}$ hollow spheres for non-volatile electrolyte-based dye-sensitized solar cells, J. Power Sources 194 (1) (2009) 574-579.

[7] A. Ghicov, et al., $\mathrm{TiO}_{2}$ nanotubes in dye-sensitized solar cells: critical factors for the conversion efficiency, Chem. Asian J. 4 (4) (2009) 520-525.

[8] G. Tsekouras, et al., Charge transport in dye-sensitized solar cells based on flamemade $\mathrm{TiO}_{2}$ nanoparticles, Selected Topics in Quantum Electronics, IEEE J. of 16 (6) (2010) 1641-1648.

[9] J. Li, J.Z. Zhang, Optical properties and applications of hybrid semiconductor nanomaterials, Coord. Chem. Rev. 253 (23-24) (2009) 3015-3041.

[10] H.-J. Chen, et al., Separable and recyclable meso-carbon@TiO ${ }_{2} /$ carbon fiber composites for visible-light photocatalysis and photoelectrocatalysis, Sustain. Mater. Technol. 21 (2019), e00105.

[11] G.K. Mor, et al., Use of highly-ordered $\mathrm{TiO}_{2}$ nanotube arrays in dye-sensitized solar cells, Nano Lett. 6 (2) (2006) 215-218.
[12] J.-H. Yun, L. Wang, R. Amal, Y.H. Ng, One-dimensional $\mathrm{TiO}_{2}$ nanostructured Photoanodes: from dye-sensitised solar cells to Perovskite solar cells, Energies 9 (12) (2016) 1030.

[13] J. Zhang, et al., An efficient photoanode consisting of $\mathrm{TiO}_{2}$ nanoparticle-filled $\mathrm{TiO}_{2}$ nanotube arrays for dye sensitized solar cells, J. Power Sources 268 (2014) 941-949.

[14] K.K. Kefeni, B.B. Mamba, Photocatalytic application of spinel ferrite nanoparticles and nanocomposites in wastewater treatment: review, Sustain. Mater. Technol. 23 (2020), e00140.

[15] J.M. Macak, H. Tsuchiya, A. Ghicov, P. Schmuki, Dye-sensitized anodic $\mathrm{TiO}_{2}$ nanotubes, Electrochem. Commun. 7 (11) (2005) 1133-1137.

[16] P. Maggie, et al., Backside illuminated dye-sensitized solar cells based on titania nanotube array electrodes, Nanotechnology 17 (5) (2006) 1446

[17] J.-H. Yun, I.K. Kim, Y.H. Ng, L. Wang, R. Amal, Optical modeling-assisted characterization of dye-sensitized solar cells using $\mathrm{TiO}_{2}$ nanotube arrays as photoanodes, Beilstein J. Nanotechnol. 5 (2014) 895-902.

[18] J. Zhang, et al., Transfer and assembly of large area $\mathrm{TiO}_{2}$ nanotube arrays onto conductive glass for dye sensitized solar cells, J. Power Sources 247 (2014) 807-812.

[19] G. Zu, et al., Highly efficient mass determination of $\mathrm{TiO}_{2}$ nanotube arrays and its application in lithium-ion batteries, Sustain. Mater. Technol. 18 (2018), e00079.

[20] M. Paulose, et al., Application of highly-ordered $\mathrm{TiO}_{2}$ nanotube-arrays in heterojunction dye-sensitized solar cells, J. Phys. D. Appl. Phys. 39 (12) (2006) 2498.

[21] Y. Sun, et al., Polymer bulk heterojunction solar cells: function and utility of inserting a hole transport and electron blocking layer into the device structure, J. Mater. Chem. 21 (5) (2011) 1365-1367.

[22] M. Dubey, H. He, Morphological and Photovoltaic Studies of $\mathrm{TiO}_{2}$ NTs for High Efficiency Solar Cells, INTECH Open Access Publisher, 2012

[23] S. Mathew, et al., Dye-sensitized solar cells with $13 \%$ efficiency achieved through the molecular engineering of porphyrin sensitizers, Nat. Chem. 6 (2014) 242.

[24] K. Gao, et al., Deep absorbing Porphyrin small molecule for high-performance organic solar cells with very low energy losses, J. Am. Chem. Soc. 137 (23) (2015) $7282-7285$

[25] K. Gao, et al., Multi-length-scale morphologies driven by mixed additives in Porphyrin-based organic Photovoltaics, Adv. Mater. 28 (23) (2016) 4727-4733.

[26] N.R. de Tacconi, et al., Photoelectrochemical behavior of Polychelate Porphyrin Chromophores and titanium dioxide nanotube arrays for dye-sensitized solar cells, J. Phys. Chem. C 113 (7) (2009) 2996-3006.

[27] S. Wenger, et al., Coupled optical and electronic Modeling of dye-sensitized solar cells for steady-state parameter extraction, J. Phys. Chem. C 115 (20) (2011) 10218-10229.

[28] C.C. Stoumpos, C.D. Malliakas, M.G. Kanatzidis, Semiconducting tin and Lead iodide Perovskites with organic Cations: phase transitions, high Mobilities, and nearinfrared Photoluminescent properties, Inorg. Chem. 52 (15) (2013) 9019-9038.

[29] W.M. Campbell, et al., Highly efficient Porphyrin sensitizers for dye-sensitized solar cells, J. Phys. Chem. C 111 (32) (2007) 11760-11762.

[30] Q. Wang, et al., Efficient light harvesting by using green Zn-Porphyrin-sensitized Nanocrystalline $\mathrm{TiO}_{2}$ films, J. Phys. Chem. B 109 (32) (2005) 15397-15409.

[31] M.J. Griffith, et al., Cation exchange at semiconducting oxide surfaces: origin of lightinduced performance increases in porphyrin dye-sensitized solar cells, J. Phys. Chem. C 117 (23) (2013) 11885-11898.

[32] J.-H. Yun, Y.H. Ng, R.J. Wong, R. Amal, Reduced Graphene oxide: control of water miscibility, conductivity, and defects by Photocatalysis, ChemCatChem 5 (10) (2013) 3060-3067.

[33] J.-H. Yun, R.J. Wong, Y.H. Ng, A. Du, R. Amal, Combined electrophoretic depositionanodization method to fabricate reduced graphene oxide- $\mathrm{TiO}_{2}$ nanotube films, RSC Adv. 2 (21) (2012) 8164-8171.

[34] T. Noeiaghaei, et al., The influence of geometrical characteristics on the photocatalytic activity of $\mathrm{TiO}_{2}$ nanotube arrays for degradation of refractory organic pollutants in wastewater, Water Sci. Technol. 71 (9) (2015) 1301-1309.

[35] A. Hinsch, et al., Long-term stability of dye-sensitised solar cells, Prog. Photovolt. Res. Appl. 9 (6) (2001) 425-438.

[36] P. Wang, et al., Amphiphilic ruthenium sensitizer with 4,4'-Diphosphonic Acid-2,2'bipyridine as anchoring ligand for Nanocrystalline dye sensitized solar cells, J. Phys. Chem. B 108 (45) (2004) 17553-17559.

[37] M.I. Asghar, et al., Review of stability for advanced dye solar cells, Energy Environ. Sci. 3 (4) (2010) 418-426.

[38] P. Wang, et al., A stable quasi-solid-state dye-sensitized solar cell with an amphiphilic ruthenium sensitizer and polymer gel electrolyte, Nat. Mater. 2 (6) (2003) 402-407.

[39] P. Wang, et al., A high molar extinction coefficient sensitizer for stable dyesensitized solar cells, J. Am. Chem. Soc. 127 (3) (2005) 808-809.

[40] R. Steim, F.R. Kogler, C.J. Brabec, Interface materials for organic solar cells, J. Mater. Chem. 20 (13) (2010) 2499-2512

[41] B.R. Ambre, B.S. Mane, C.-H. Hung, Zinc porphyrins possessing three pcarboxyphenyl groups: effect of the donor strength of push-groups on the efficiency of dye sensitized solar cells, Energies (2016) 9(7).

[42] G.F. Burkhard, E.T. Hoke, M.D. McGehee, Accounting for interference, scattering, and electrode absorption to make accurate internal quantum efficiency measurements in organic and other thin solar cells, Adv. Mater. 22 (30) (2010) 3293-3297.

[43] D. Kuang, et al., Application of highly ordered $\mathrm{TiO}_{2}$ nanotube arrays in flexible dyesensitized solar cells, ACS Nano 2 (6) (2008) 1113-1116.

[44] A.J. Mozer, et al., The origin of open circuit voltage of porphyrin-sensitised $\mathrm{TiO}_{2}$ solar cells, Chem. Commun. 39 (2008) 4741-4743.

[45] I. Chung, et al., All-solid-state dye-sensitized solar cells with high efficiency, Nature 485 (7399) (2012) 486-489. 
[46] E.-H. Kong, et al., Aerosol OT/water system coupled with Triiodide/iodide $\left(\mathrm{I}_{3}^{-} / \mathrm{I}^{-}\right)$ redox electrolytes for highly efficient dye-sensitized solar cells, Adv. Energy Mater. 3 (10) (2013) 1344-1350.

[47] B. Lee, et al., Materials, interfaces, and photon confinement in dye-sensitized solar cells, J. Phys. Chem. B 114 (45) (2010) 14582-14591.

[48] Q. Zhang, G. Cao, Nanostructured photoelectrodes for dye-sensitized solar cells, Nano Today 6 (1) (2011) 91-109.

[49] K. Park, et al., Charge transport properties in $\mathrm{TiO}_{2}$ network with different particle sizes for dye sensitized solar cells, ACS Appl. Mater. Interfaces 5 (3) (2013) 1044-1052.

[50] P. Roy, et al., $\mathrm{TiO}_{2}$ nanotubes and their application in dye-sensitized solar cells, Nanoscale 2 (1) (2010) 45-59.
[51] J.-H. Yun, Y.H. Ng, C. Ye, A.J. Mozer, G.G. Wallace, R. Amal, Sodium fluoride-assisted modulation of anodized $\mathrm{TiO}_{2}$ nanotube for dye-sensitized solar cells application, ACS Appl. Mater. Interfaces 3 (5) (2011) 1585-1593.

[52] J.R. Jennings, et al., Dye-sensitized solar cells based on oriented $\mathrm{TiO}_{2}$ nanotube arrays: transport, trapping, and transfer of electrons, J. Am. Chem. Soc. 130 (40) (2008) 13364-13372.

[53] M. Pazoki, et al., Characterization techniques for dye-sensitized solar cells, Energy Environ. Sci. 10 (3) (2017) 672-709.

[54] M. Adachi, et al., Determination of parameters of Electron transport in dyesensitized solar cells using electrochemical impedance spectroscopy, J. Phys. Chem. B 110 (28) (2006) 13872-13880. 